\title{
La belleza salvará al mundo
}

\section{Beauty will save the world}

\section{A beleza salvará ao mundo}

\author{
François Fédier ${ }^{2}$ \\ Traducción de Jorge Acevedo Guerra ${ }^{3}$
}

\begin{abstract}
Nota preliminar
Este texto es una conferencia que François Fédier pronunció el 9 de mayo de 2001 en la Universidad Bocconi de Milán. Desde 1998, el profesor Gino Zaccaria invitó anualmente a François Fédier para un seminario de trabajo en torno al tema «totalitarismo y nihilismo». Esta conferencia tuvo lugar para clausurar el último año, en el que también fue invitado a participar Henri Crétella. El conjunto de textos que produjo François Fédier con ocasión de este seminario ha sido recogido en una obra publicada en italiano por Maurizio Borghi bajo el título Totalitarismo e nichilismo.
\end{abstract} Tre seminari e una conferenza, Como-Pavia, Ibis, 2003.

Del «Prefacio» de Hadrien France-Lanord a L'art en liberté, pp. 13 s.

\section{Translation by Jorge Acevedo Guerra}

\section{Preliminary note}

This text is a conference that François Fédier delivered on May 9, 2001 at Bocconi University in Milan. Since 1998, Professor Gino Zaccaria has invited François Fédier to an annual seminar on "totalitarianism and nihilism".

1 En «L'art en liberté. Aristote, Baudelaire, Proust, Flaubert, Cézanne, Kant, Matisse, Heidegger», Pocket, París, 2006; pp. 311-333. A menos que se indique otra cosa, todas las notas son del traductor. Sus indicaciones van entre corchetes [ ]. En las dos ocasiones en que F. Fédier los utiliza, han sido reemplazados por llaves \{\} . Las palabras escritas en griego en el original han sido transliteradas en la versión en castellano.

2 Nacido en 1935, estudió con Jean Beaufret desde 1955. Se ha consagrado, a partir de 1958, a la traducción de textos de Martin Heidegger. Profesor de filosofía hasta su retiro en 2001, ha traducido también los poemas de Friedrich Hölderlin. Acerca de él: Hadrien France-Lanord y Fabrice Midal (editores). La fête de la pensée. Hommage à François Fédier, Lettrage Distribution, Paris, 2001. En una próxima fecha aparecería su libro «Voz del amigo y otros ensayos en torno a Heidegger» (Ediciones de la Universidad Diego Portales, Santiago de Chile), obra editada por Jorge Acevedo Guerra.

3 Chileno. Profesor titular de la Universidad de Chile. Elegido director de su Departamento de Filosofía en sucesivos periodos entre 1989 y 1993 y entre 1995 y 2008. E-mail: joacev@gmail.com 
This conference took place to close the last year and Henri Crétella was also invited to participate. The set of texts produced by François Fédier on the occasion of this seminar has been collected in a work published in Italian by Maurizio Borghi under the title Totalitarismo e nichilismo. Tre seminari e una conferenza, Como-Pavia, Ibis, 2003.

From the "Preface" by Hadrien France-Lanord to L'art en liberté, pp. 13 s.

\section{Tradução de Jorge Acevedo Guerra}

\section{Nota preliminar}

Este texto é uma conferência que François Fédier pronunciou o 9 de maio de 2001 na Universidade de Bocconi, em Milão. Desde 1998, o professor Gino Zaccaria convidou anualmente a François Fédier para um seminário de trabalho sobre o tema "totalitarismo e niilismo". Esta conferência teve lugar para clausurar o último ano, onde também foi convidado a participar Henri Crétella. O conjunto de textos que produz François Fédier durante este seminário foi coletado num livro publicado em italiano por Maurizio Borghi com o titulo Totalitarismo e nichilismo. Tre seminari e um conferenza, Como-Pavia, Ibis, 2003.

Do "Prefácio" de Hadrien France-Lanord a L'art en liberté, pp. 13 s.

Este año, el trabajo que hacemos juntos desde hace cuatro años no tendrá lugar como las últimas veces: hoy no se trata de un seminario, sino de una conferencia.

Sin embargo, a pesar de este cambio de forma, de hecho se prosigue con el mismo trabajo. Por eso voy a comenzar por recordar lo que hemos intentado columbrar hasta ahora. Pero permítanme primero una palabra sobre el trabajo que acabo de evocar, a saber, el trabajo de seminario. Aunque ya hemos practicado tres veces ese ejercicio, corremos siempre el riesgo, en efecto, de no haber vislumbrado bien la virtud principal de un seminario.

¿Cuál es esta virtud? Muy simplemente, consiste en invitar a cada uno de los participantes a hacer frente -con la presencia de espíritu de que es capaz con seguridad en cada momento-, lo que se ofrece para ser pensado. En este sentido, el seminario -donde varios están juntos para intentar poner en común sus esfuerzos a propósito de un tema de reflexión bien real- es una ocasión sin igual para probar que pensar no es, en primer lugar, una actividad subjetiva -incluso, solipsista- sino que implica siempre a otro. 
Por lo pronto, por hábito, entendemos a este otro como un alter ego. $Y$ como en un seminario somos numerosos, y como cada uno es otro, la sola diversidad de individuos augura un posible enriquecimiento mutuo. Lejos de mí la idea de desdeñar este aspecto; en una época de individualismo desenfrenado, es bueno prestar atención a lo que, desde ya, puede tener de positivo un verdadero trabajo colectivo aunque esta expresión de «trabajo colectivo» amenaza con llevarnos en una dirección exactamente opuesta a aquella hacia donde busco ir.

Porque este otro de que hablo no es en primer lugar un alter ego. ¿Cómo hacer entender el sentido de alteridad de este alter sin pasar por el ego? Recuerdo haber leído en un curso de Heidegger una frase que ayuda a disipar la neblina que envuelve esta cuestión. Esta es la frase -tal como guardo memoria de ella-:

«A es diferente de B. Sea. Pero si A y B -tanto el uno como el otro- no fueran totalmente diferentes del es, no podrían ni siquiera aparecer como diferentes el uno del otro».

En otros términos: toda diferencia óntica (toda diferencia entre entes) presupone la diferencia ontológica (la diferencia entre lo que es y el ser-mismo).

Así, pues, los invito a considerar esto: la situación de estar juntos para trabajar en común (esta situación que Platón llama ouvouoía [synousía]) es una posibilidad insigne de hacer la experiencia de esta alteridad fundamental que Heidegger llama «diferencia ontológica». Para comenzar, notemos que, en consecuencia, siempre será preciso el esforzarse por mirar de otra manera la alteridad: de otra manera de la que, habitualmente, la aprehendemos, de otra manera que según la diferencia que nos obnubila, es decir, la diferencia entre dos entes. Así, más bien que fijarnos en la diferencia de «puntos de vista», intentemos medir la diferencia de todo punto de vista con lo que es. Para esto, no desatendamos, sobre todo, la disponibilidad que ofrece el hecho de ser varios; no varios individuos particulares, sino varios seres humanos, es decir, varias oportunidades de estar atentos a la verdadera alteridad. Porque es, por así decirlo, el sello de la manera singular de ser que nos caracteriza a nosotros los hombres el poder 
estar orientados respecto de la diferencia ontológica a partir del solo hecho de que nos es imposible existir sin tener que estar-juntos.

El primer ejercicio al que nosotros nos hemos confrontado juntos, recordémoslo, ha consistido en la tentativa de contrastar la idea de totalitarismo, tal como la entendemos hoy día, con su comprensión más antigua, la que reinaba antes de que los «sistemas totalitarios» hubieran, finalmente, revelado en toda su amplitud su naturaleza criminal.

$Y$ en él, el primer resultado de nuestro examen ha sido constatar que antes de esta revelación (que ha sido completa para el nazismo desde el fin de la Segunda Guerra mundial; los regímenes llamados «comunistas» han conseguido pasar por «globalmente positivos» hasta los comienzos de los años 70), el término «totalitarismo» no era percibido como unívocamente peyorativo. Recuerdo, para fijar bien esta adquisición, el muy sorprendente discurso del papa Pío XI, dirigido a los sindicalistas cristianos hacia 1938, en el que declara: «La Iglesia también es totalitaria».

Comprendan bien el sentido en el que ha sido hecha esta observación. En mi opinión-sobre todo tratándose del papa Pío XI, quien ha pedido al cardenal Pacelli redactar la encíclica «Mit brennender Sorge»- está fuera de lugar entregarnos a algún sarcasmo, el que fuere.

Esto nos lleva a la segunda observación: si se exige de nosotros -para que entendamos el término «totalitarismo» como lo entendían los contemporáneos de Pío XI- poner fuera de juego el sentido en el cual hoy día todo el mundo percibe esta palabra por anticipado, es preciso que podamos reconstituir qué podía haber en ella de positivo. Nada es, en efecto, más simple; basta rememorar en qué contexto y a partir de dónde toma su sentido la idea de «totalitario». Ahora bien, ese contexto y ese dominio no son otros que el de la Lógica filosófica, y más precisamente, de aquel que, desde la aclimatación de la Lógica en el lenguaje escolástico, se llama lo universal.

Mi tesis, si quieren aceptar de buen grado esta denominación un poco pomposa, es que el pensamiento de lo «totalitario» es la extrema 
vicisitud del viejo tema lógico de lo universal. He ahí lo que abriría muchas pistas muy interesantes de investigación a los filósofos de profesión; por ejemplo, la exacta puesta a punto de los conceptos gracias a los cuales los filósofos articulan la noción de «totalidad». Así, Kant adopta un particular cuidado al distinguir en el seno mismo de la totalidad varias acepciones muy diferentes, de tal modo que la palabra totalidad reúne significaciones heterogéneas (tanto universalitas como universitas -para decirlo con las palabras latinas-). Lo implícito de estas tesis es que el pensamiento filosófico no ha sido apto para conservar a lo universal el estatuto eminente que debería ser el suyo, y que ha dejado caer cuesta abajo lo universal en dirección de la uniformidad. ¿Por qué? No es ocioso preguntarse sobre esta carencia, tanto más cuanto que ello nos permite hacer una importante advertencia sobre la tarea propia de la filosofía.

Es, en efecto, una de las ideas recibidas más incorregibles aquella que hace creer que la filosofía tendría por función suministrar los instrumentos conceptuales gracias a los cuales la humanidad afrontaría los «problemas» inherentes a su condición. No hay tal vez urgencia más grande para nosotros, en la época en que nos encontramos en el presente, que despertarnos de esa ilusión mayor. El «sueño dogmático» del que hablaba Kant no es nada al lado del uniforme sonambulismo en que estamos todos hoy día en relación al pensamiento. Por eso es indispensable recordarnos sin cesar lo que decía Heidegger hace, ahora, ya cincuenta años:

«Lo que hay de más inquietante en nuestra época inquietante, y que debería dar lo más en qué pensar, es que nosotros no pensamos aún». ${ }^{4}$

A propósito de eso, nada nos puede situar como es preciso respecto de este tema que la conveniencia de comenzar por abandonar los hábitos que nos impiden pensar -antes, inclusive, de ponernos a pensar, y para disponernos a ello-. Lo que importa para nosotros,

4 Cfr. M. Heidegger. ¿Qué significa pensar?, Ed. Trotta, Madrid, 2005, Lección I, p. 17. Trad. de Raúl Gabás. 
aquí y ahora, es darnos bien cuenta de que es precisamente a eso a lo que se consagra el trabajo que hacemos juntos: en plena conciencia nos ejercitamos en abandonar los hábitos que nos impiden pensar.

Acabo de mencionar antes que la noción de «totalidad»-tal como ha terminado de imponerse través del siglo XX- derivaba del pensamiento filosófico de lo universal dejado correr cuesta abajo. Ahora bien, todo ocurre hoy como si nadie viera en el «totalitarismo» algo más que la negación de lo universal, de tal modo que mi proposición aparece como una especie de paradoja. Lo que querría, pues, que examináramos con la mayor atención es este asunto, inquietante él mismo, y que intentaré formular tan claramente como pueda: mientras que la noción de universal nos parece ser la garantía misma de la humanidad (Menschlichkeit), ocurre, sin embargo, que el totalitarismo deriva de ella, es decir, la matriz de lo que aprehendemos como el arquetipo del comportamiento criminal por excelencia.

¿Cómo ha pasado esto? ¿Es posible señalar las etapas de este brutal descenso? Tratemos de ver. Permítanme una petición: sobre todo, no vean en lo que va a seguir un empeño de erudición. Lo que se trata de poner en la luz es mucho más importante. En ello se trata nada menos que de nuestra historia o, más bien, de lo que gobierna secretamente nuestra historia.

«Universal» es el calco del término universalis, el cual, al parecer, aparece en Quintiliano, para traducir lo que los Griegos de su tiempo -es decir, de la época helenística (y, más precisamente, los lógicos del

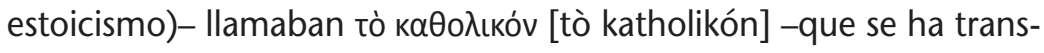
puesto tal cual en nuestra palabra «católico». Aristóteles no emplea

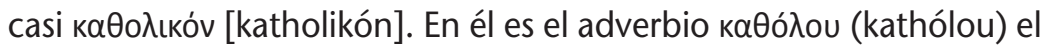
que juega un papel decisivo en la puesta a punto de la mirada filosófica

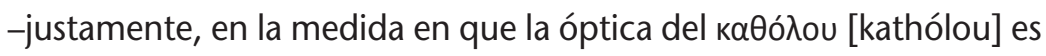
aquella que toma en vista «según el Todo»-. El neutro Universum, en los Latinos, ha servido de traducción al griego tò ő̉ov [tò hólon] (el Todo en tanto que entero). La simple lectura del admirable Diccionario etimológico de la lengua latina, de Alfred Ernout y Antoine Meillet, permite ya una observación decisiva. En el artículo «universus», estos 
eminentes filólogos anotan: «propiamente "vuelto totalmente entero (de un único impulso) hacia"». Esta observación nos enseña que en la palabra latina universus el elemento uni- no designa aquello hacia lo cual está vuelta la mirada sino la modalidad según la cual la mirada misma se vuelve: cómo se está con respecto de eso hacia lo cual se está vuelto cuando es de una manera «universal»: se está vuelto de una sola pieza; dicho de otra manera, se está enteramente vuelto.

¿Qué vemos aquí? En primer lugar esto, que es de gran importancia: la lengua latina, como todas las lenguas humanas, está llena de sorprendentes recursos. El término universus, tal como podemos oírlo hablar nativamente en latín, no pide sino conducir el pensamiento hacia una comprensión del fenómeno cardinal que está en juego cuando se

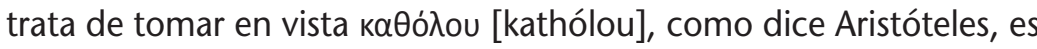
decir, en la óptica del Todo. Pero para llegar allí es preciso acompañar, pensándolo, lo que se encuentra ya en bosquejo en el vocablo, y que nosotros podemos alcanzar como sigue; haciendo hincapié, simplemente, en lo que no espera sino encontrar su formulación: la única condición en la que puede tener lugar un tomar en vista filosó-

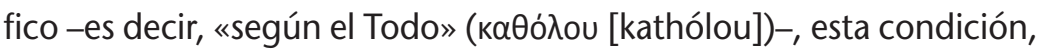
digo, no es otra que una mirada vuelta entera por completo (de un único impulso) hacia el Todo. Lo que también debe completarse así: esta condición primordial no es pensable sin que ella misma esté condicionada, de tal modo que el Todo no puede ser dicho como precediendo a la mirada que toma en vista el Todo, como tampoco esta última podría ser, de alguna manera, anterior al Todo que toma en vista. En otros términos: el Todo -blanco de la mirada propiamente filosófica- no es pensable independientemente de la mirada misma; o, si se quiere: este Todo incluye por anticipado la mirada del Todo.

Esto es decir que este Todo no es, en absoluto, visible en una perspectiva de suma, por adición de elementos que vienen a juntarse los unos con los otros. Esto es, pues, decir que estamos ahí frente a un fenómeno de naturaleza completamente singular, y, del todo, particularmente diferente de todos los fenómenos que habitualmente consideramos como capaces de ejemplificar una totalidad. Llamo la atención de ustedes sobre la relación de esto que acaba de ser 
dicho con la diferencia ontológica de la que se ha hecho cuestión anteriormente.

Pero es preciso, también, agregar a la advertencia que recién fue hecha la pregunta que acaba de darle su alcance: ¿podemos com-

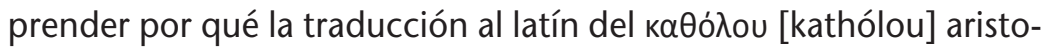
télico entraña el descenso de que hemos hablado? Ahí, de nuevo, es posible señalar uno de los puntos más mal comprendidos de la doctrina de Heidegger.

La opinión que se ha extendido por todas partes es que Heidegger haría responsable a la traducción al latín del pensamiento griego de la baja de nivel que imprime su sello definitivamente a lo que se ha convenido en llamar «el olvido del ser». No vacilo en calificar esta opinión de caricatura, inclusive de estupidez. La verdad -que va exactamente en contra de ese contrasentido- es esta: el pensamiento griego no ha sido traicionado porque los Romanos hayan traducido al latín los vocablos griegos. Lo ha sido porque los Romanos han intentado esta traducción sin permanecer fieles al espíritu de su lengua; o, quizás aún más claramente: porque no han tenido el coraje -o la audacia-, de buscar todo lo que, en su lengua, respondía nativamente a lo que los pensadores griegos han logrado en su lengua -por cierto, magistralmente-. En otros términos: la falta de los Romanos consiste en haber pensado, ingenuamente, que debían ir a la escuela de quienquiera que sea prescindiendo de un aprendizaje primordial: el que pide desplegar también-tan explícitamente como sea posible-su propia popularidad.

No es casual que se imponga aquí la palabra del poeta Hölderlin. En él, «Popularität» -una palabra característicamente latina-, debe entenderse como lo que imprime su sello a la relación posible de cada pueblo respecto del Todo-entero que nombra el kaӨó̀ou [kathólou] de Aristóteles. La falta romana (que tiene un alcance histórico si es que no, inclusive, historial) es así, en primer lugar, una falta cometida en contra de la popularidad romana. No tendría ningún sentido hacer esta advertencia si nosotros mismos no nos encontráramos en una situación simétrica. Toda nuestra concepción de la «cultura» está fundada sobre esta verdadera estadía en falso de la que los Romanos son los iniciadores: creer que adquirir un saber puede tener lugar por 
absorción, como si el saber fuera un bien disponible, que bastaría con transponer. Mientras que, en verdad, se trata de encontrar en el seno de su propia popularidad, eso que se ajusta, antes de todo aprendizaje, a lo que se trata de aprender explícitamente.

Desde la cuestión que nos ocupaba durante el primer seminario -la cuestión que giraba alrededor de la noción de totalitarismo-, puedo formular en el momento presente de manera más clara lo que es mi único propósito.

A lo largo de todo el camino que ha trazado, Heidegger ha recordado constantemente, en una formulación estricta, lo que debe ser admitido de la filosofía como metafísica bajo su forma más acabada (es decir, en la culminación que es el pensamiento de Aristóteles). La filosofía, repite él en consecuencia, es el saber que toma en vista «das Seiende als solches im Ganzen». ${ }^{5}$

Se ha tomado el hábito de traducir: «el ente como tal en totalidad». Desde hace años he señalado que esta traducción es profundamente desorientadora. Pero esto no ha sido siempre tomado en consideración; sin duda, porque no he sabido decirlo bastante claramente. Por eso vuelvo hoy día sobre ello, solicitando toda su atención: esta

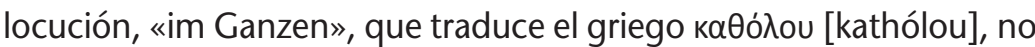
nos es permitido traducirla en nuestras lenguas latinas por el término totalidad. Porque «totalidad» es precisamente la palabra en la que se situó la desviación que irremediablemente, cada vez más, aleja al pensamiento occidental de lo que veía Aristóteles a través del término

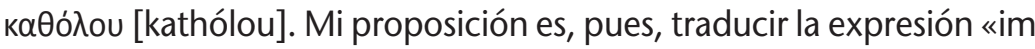
Ganzen» por «por entero» [«en entier»].

La filosofía es el saber que toma en vista el ente como tal por entero. Das Ganze, die Ganzheit -al menos en Heidegger, puesto que estas palabras son las palabras alemanas que son las suyas- es necesario

5 Véase, por ejemplo, «La constitución onto-teo-lógica de la metafísica». En Identidad y Diferencia (ed. bilingüe), Ed. Anthropos, Barcelona, 1988, p. 150. Trad. de Helena Cortés y Arturo Leyte 
no traducirlas a partir de nuestra idea de totalidad, sino a partir de la de integridad [entièreté]. La palabra existe en francés antiguo ${ }^{6}$. Me sorprendería mucho que estuviera ausente de su lengua italiana. Porque es simplemente imposible que una lengua no conozca, bajo una forma u otra, esa relación a lo entero que imprime su sello al modo de ser de todo lo que es humano.

La integridad es el carácter de lo que es entero -es decir, de eso a lo que no le falta nada para ser-. Habíamos dicho anteriormente, a propósito del adjetivo universus, que esta palabra designaba espléndidamente la actitud o el mantenerse de quien está en relación con la integridad: universus = vuelto de modo unificado, es decir, enteramente vuelto hacia lo entero. Tomar en vista al ente como tal por entero no es intentar comprenderlo a partir de una totalidad; es, más bien, simplemente, articular un «saber» que no es más que uno con la condición humana. ¿Podemos aún llamarlo un «saber»? ¡En nuestras lenguas romances, ciertamente, si es que estamos atentos a lo que ellas dicen! Así, ese saber habla en el seno del vocablo universus, en su acepción original. Dejemos a Hölderlin decírnoslo en alemán:

«Wer nur mit der ganzen Seele wirkt, irrt nie».

[«No se desorienta jamás quien solamente hace de toda su alma lo que debe hacer»].

Hyperion, II, 1 \{Hellingrath II, p. 218\}

Es imposible entender lo que dice el poeta si viene a interferir la idea de totalidad. Esto permite una nueva advertencia: en nuestras lenguas, la diferencia entre el Todo (es decir, el Todo en cuanto integridad) y la totalidad, es uno de esos matices inaparentes de los que Husserl

\footnotetext{
${ }^{6}$ Entièreté: 1. Intégralité, totalité, état d'une chose qui est dans son entier. 2. Intégrité, état d'une chose qui ne souffre d'aucune restriction (DMF: Dictionnaire du Moyen Français (DMF 2015), http://www.atilf.fr/dmf, ATILF - CNRS \& Université de Lorraine).

7 Cfr., F. Hölderlin: Hiperión o El eremita en Grecia, Ediciones Hiperión, Madrid, 10 ${ }^{\text {a }}$ ed., 1988. Volumen segundo, Libro primero, «Hiperión a Diótima (2a comunicación)». Trad. de Jesús Muñárriz.
} 
señalaba que con ellos se deciden, en el pensamiento, sus callejones sin salida y sus aperturas.

Tratemos aquí de decir, tan clara y simplemente como sea posible, de qué se trata con esta traducción. Traduttore traditore es, precisamente, un proverbio italiano que conozco. ¡Y bien!, hablemos de la traición traductora. Se cree que ésta consistiría en no ser «fiel», como se dice, a lo que se halla en la lengua de que se traduce. Esta traición es (medida desde el alcance de la cuestión que planteamos) de un orden que, sin vacilar, es preciso calificar de subalterna. Mucho más grave es la traición que, sin cesar, nos arriesgamos a cometer cuando no permanecemos fieles a la riqueza que albergan nuestras lenguas. Lo que digo, en consecuencia, es que nosotros, gentes del ámbito latino, cuando traducimos Ganzheit por «totalidad», traicionamos el espíritu de nuestras lenguas, al no pensar, simplemente, en lo que en ellas va ya -por así decirlo, a nuestra espalda- en dirección de la verdadera comprensión del Todo, es decir, de la integridad. Este tipo de traición ya ha tenido lugar cuando los Romanos intentan traducir las palabras de la filosofía griega sin partir de lo que estaba en condiciones de decir la lengua latina. Eso es lo que esclarece, pienso, el propósito de Heidegger cuando habla de la traducción de la filosofía al latín. Todos sabemos que dice y repite que esta traducción es un acontecimiento desastroso; pero también casi toda la gente interpreta esto en un sentido verdaderamente imbécil: como una condenación que emitiría Heidegger acerca de las lenguas latinas (incapaces, se añade, de pensar verdaderamente). Esta cuestión es de tal importancia que es preciso no dejar cernirse sobre ella la menor duda. El reproche de Heidegger no se emite sobre las lenguas latinas, sino sobre la actitud de los Romanos respecto de la cultura griega. En efecto, los Romanos (instituyendo en esto algo que se va a perpetuar en Europa) han comprendido el conjunto de las obras del espíritu griego como «cultura» $y$, sobre todo, como modelo de cultura, como modelo a seguir para elevarse tanto como es posible al mismo nivel que el de sus iniciadores griegos. Al mirarlo atentamente, vemos que este enfoque romano es ya el de la «división del trabajo»: se trata de localizar dónde y cómo se obtiene de una manera óptima un resultado fuera de lo común, con el fin, simplemente, 
de reproducir lo que ya ha sido hecho. Ahora bien, tal división del trabajo -la que implica la posibilidad de su división, de tal modo que en lo sucesivo tal grupo de hombres esté encargado de las tareas donde se destaca, mientras que las otras tareas (en las que es menos eficaz) son reservadas a otros grupos-, tal concepción del trabajo, digo, es insostenible, por la razón de que rebaja al trabajo a no ser más que una actividad. Se mantiene así el criterio más seguro de todo trabajo real: es verdadero trabajo todo el que no se deja dividir.

Para ilustrar aún más claramente lo que acaba de ser dicho sobre la traición por parte de los Romanos de su propia popularidad; para establecer bien que hablar de esta traición no tiene lugar con el estúpido objetivo de rebajar la latinidad sino, todo lo contrario, con el fin de que prestemos atención a los riesgos que nos amenazan cuando acometemos la formidable tarea de pensar el acontecimiento que ha sido la historia entera del pensamiento metafísico; para eso, digo, agreguemos unas líneas que apuntan hacia una de las formulaciones más herméticas de Hölderlin.

En la primera carta a su amigo Böhlendorf (fechada el 4 de diciembre de 1801), Hölderlin habla de Homero, el primer poeta griego («el poeta de todos los poetas»), como ha escrito en otra parte (Hellingrath, III, 274) ${ }^{8}$, y de lo que ha hecho Homero para instituir la poesía griega. Homero, dice, ha llevado a su cima el don de exponer (darstellen), es decir, de poner ahí, de modo tal que es hecho patente aquello que se expone. Y también explica por qué (abramos los oídos):

«Porque este hombre extraordinario era lo bastante amplio de alma como para ir a apoderarse de la sobriedad occidental junoniana a favor de su reino de Apolo». ${ }^{9}$

8 Cfr. F. Hölderlin, «[Sobre Aquiles, 2]». En Ensayos, I. Peralta Ediciones, Pamplona / Editorial Ayuso, Madrid, Colección Libros Hiperión, 1976, p. 37. Trad. de Felipe Martínez Marzoa.

9 Cfr., F. Hölderlin. «Dos cartas». En Ensayos, ed. cit., p. 126. / F. Hölderlin. Correspondencia completa, Ediciones Hiperión, Madrid, 1990, p. 553. Trad. de Helena Cortés y Arturo Leyte. 
Este hombre extraordinario es Homero. Es extraordinario porque es apto para hacer lo que nosotros los hombres, ordinariamente, somos incapaces de hacer: abrir hasta tal punto nuestra alma que estemos abiertos a lo que es otro que nosotros mismos. En eso está, en efecto, la proeza de Homero: él es, escribe Hölderlin, «seelenvoll»-literalmente, «lleno de alma»-, lo que debemos comprender como designando una plenitud de apertura, es decir, una plenitud de pura acogida, es decir, una plenitud de disponibilidad. Así es como él está en condiciones de hacer venir a su reino de Apolo la sobriedad occidental.

Nos arriesgamos a entender el reino de Apolo (Apollonsreich) a contrasentido si lo interpretamos con ayuda de la oposición que establecerá Nietzsche, a saber, la del contraste entre lo apolíneo y lo dionisíaco. Es por eso que lo más prudente para parar en seco esa intelección sería formular abruptamente esto: el «reino de Apolo» es el reino de la inmediatez (del que el símbolo nietzscheano es, precisamente, lo dionisíaco). Este reino de inmediatez no es otro que el ámbito nativo de los Griegos.

Hölderlin tiene el cuidado de calificar de junoniana la sobriedad occidental -a partir del nombre, en consecuencia, de la divinidad romana.

Lo que nosotros vislumbramos ahí es propiamente vertiginoso. Digámoslo de una manera que va a hacernos presente ese vértigo: según lo que expone Hölderlin, Homero es el que instituyó la poesía griega en cuanto ha sabido, desde el inicio, hacerse maestro de lo que será la virtud occidental por excelencia: a saber, la sobriedad.

¿Dónde está lo vertiginoso? No en el anacronismo en que el futuro es anticipado (en la página 77 del Cuaderno de Homburgo, Hölderlin anota: «Nosotros colocamos las épocas / en completo desorden), sino, más bien, en el hecho de que la posibilidad de ser griega pueda demandar no ser fiel a su propia popularidad.

¿Podemos decir: «no ser fiel»? Ciertamente -con la condición de precisar también que hay dos modalidades de ser infiel, de las cuales una sola es la infidelidad que nosotros conocemos: aquella que cae en olvidar lo que no deberíamos olvidar. Mientras que la otra infidelidad 
consiste en abandonar eso. Hölderlin agrega en la última página de Observaciones sobre Edipo: «sin duda de manera santa» ${ }^{10}$.

Esto puede parecer incomprensible. Pero ahí ocurre la manera como obra el pensamiento. Acordémonos de lo que dice Heidegger en el librito titulado De la experiencia del pensar (p. 13), a saber, que el pensamiento debe, necesariamente, pensar contra él mismo ${ }^{11}$. No puede tratarse de una acción al revés o de una contradicción. Pensar a contrapendiente [à contrepente] no demanda la infidelidad de olvidar eso donde la pendiente desciende, sino aquella de no dejar de desviarnos de ello.

Dejando esta evocación de nuestro primer seminario, permítanme ahora decir una vez más: no debemos olvidar hacia lo que conduce el pensamiento de lo universal, así como tampoco de dónde viene, ni la desviación (o mejor, quizás: el despiste) que hace virar de lo uno a lo otro -pero, sobre todo, nosotros debemos aprender a abandonar o desviarnos de eso.

El segundo seminario ha sido consagrado al tema «Pensar el arte». Lo que hemos tratado de hacer se deja resumir simplemente: hemos acompañado a una de las culminaciones del pensamiento filosófico cuando toma por tema el arte, a saber, la parte de la Crítica de la fuerza [force] de juzgar que se ocupa del «juicio estético».

Lo que hemos podido constatar, punto por punto, es cómo, en los giros mismos de su formulación, Kant se enfrenta con una dificultad que lo fuerza, sin cesar, a ceñir lo que es lo bello con ayuda de determinaciones de las que hemos dicho que están, cada vez, en el límite de la contradicción. Recordemos esto con la ayuda de un solo

10 Cfr. Ensayos, ed. cit., p. 142.

11 Cfr. M. Heidegger. La experiencia del pensar seguido de Hebel, el amigo de la casa, Ediciones del Copista, Córdoba (Argentina), $2^{\mathrm{a}}$ ed. corregida, 2000, p. 35. Trad. de Arturo García Astrada. / M. Heidegger. Des de l'experiència del pensament, ed. trilingüe (catalán, alemán, castellano), Ediciones Península, Barcelona, 1986, p. 75. Trad. de Joan B. Llinares. 
ejemplo. El segundo «momento» de la elucidación de lo bello (KU, § 9, p. 32) se resume como sigue:

«Es bello lo que place universalmente sin concepto». ${ }^{12}$

Recordemos la tripartición a partir de la cual esta frase adquiere su sentido. En la página 15 de la tercera Crítica (§ 5), Kant escribe:

«Agradable es para alguien lo que [en alguna medida] lo satisface; bello, lo que simplemente le place; bueno, eso a lo que otorga su estima, su aprobación». ${ }^{13}$

Lo que, para nuestro propósito, es sorprendente es la manera en la que Kant perfila la determinación del placer experienciado en el contacto con lo bello. Lo bello, dice él, es lo que place universalmente. Para nosotros, la idea de un placer universal es casi un sinsentido, porque bajo el nombre de placer nosotros entendemos aquí la «satisfacción» (Vergnügen, donde es preciso saber escuchar hablar la palabra alemana «genug», y la latina satis). En consecuencia, lo que distingue al placer verdadero de la satisfacción es, precisamente, que el placer no se limita al individuo que lo siente. Sintiéndolo, este individuo se encuentra, de inmediato, desindividualizado. Más exactamente: el ser humano, en el contacto con lo bello, no dejando de ser este que él es, deja de ser un individuo. ¿Diremos que es «universal»? Eso ya no es necesario. Podemos aquí, por nuestra cuenta y riesgo, abandonar el lenguaje tradicional de la filosofía -ese lenguaje en que lo universal se comprende lógicamente-y podríamos intentar decir: en el contacto con lo bello, el ser humano es íntegramente él mismo.

Henos ahí de vuelta a lo que se refiere el título de esta conferencia. Es una frase de Dostoievski, que es pronunciada en el capítulo $V$ del Tercer Libro de la gran novela El Idiota. Antes de seguir adelante, querría recordar que Nicolás Gogol (por quien, como por Pushkin,

12 Cfr. I. Kant. Textos estéticos, Ed. Andrés Bello, Santiago de Chile, 1983, p. 115. Trad. de Pablo Oyarzún R. / M. Kant. Crítica del juicio, Ed. Espasa-Calpe, Colección Austral, Madrid, 1977, p. 119. Trad. de Manuel García Morente.

13 Cfr. Textos estéticos, ed. cit., p. 100. / Crítica del juicio, ed. cit., p. 108. 
Dostoievski sintió durante toda su vida un sentimiento de veneración) llamaba «Poema» a su novela Las almas muertas. Toda gran novela es otra cosa de lo que nosotros, a la ligera, llamamos «una novela» [«un roman»] (sería tiempo de que nosotros, que hablamos las lenguas romances [romanes], pensáramos seriamente en lo que es íntegramente una novela [roman].

La frase es pronunciada por un personaje que se dirige en estos términos al príncipe León Nicolaievich Michkin:

«Príncipe, ¿es verdad que usted ha dicho una vez: "Es la belleza la que salvará al mundo"?»

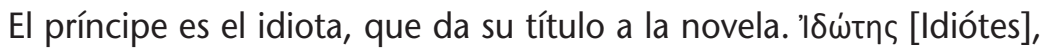
en griego, designa al ser humano en cuanto no pertenece a la colectividad, sea colectividad étnica o colectividad social. Sin embargo, no vayamos demasiado rápido, y no digamos que este ser humano es el hombre universal (aunque no fuera sino porque hablar así es, necesariamente, recurrir a una vía de abstracción). Para nosotros, su nombre debe permanecer aún: el idiota. Así, el príncipe, al comienzo de la novela (capítulo VII del Primer Libro), declara en una conversación en la casa del general Iván Fedorovich Epanchin, mientras es sometido a una especie de interrogatorio para ser admitido en la alta sociedad:

«La belleza, es difícil juzgar al respecto; yo no me encuentro preparado aún para ello. La belleza es un enigma».

Me agradaría, con toda seriedad, que ustedes no creyeran que he llegado más allá de donde está el Idiota. Kant, por el contrario, está indiscutiblemente más allá, aunque no fuera sino porque su examen de lo bello tiene lugar en el seno de una Crítica de la fuerza [force] de juzgar. El verbo soudit' (juzgar) que leemos en ruso tiene exactamente la acepción del kpiveıv [krínein] griego y kantiano.

Mis palabras no contienen ninguna ironía: para que ustedes puedan darse cuenta de ello sin el menor equívoco me basta con reiterar una vez más que la meditación filosófica de Kant es uno de los documentos más impresionantes que la metafísica ha logrado llevar a cabo en lo que concierne a la determinación de lo bello. A pesar de eso, esta 
meditación sigue siendo fundamentalmente insuficiente, y esto es así porque no alcanza a estar en claro en cuanto a la relación recíproca del pensamiento y del juicio. Kant escribe, ciertamente, que «pensar es juzgar». Pero, ¿cuál es el estatuto del juicio mismo, es decir, de la dijudication, en latín (Urteil, en alemán)? ¿Qué lo diferencia y a partir de qué diferenciación?

En tanto estas cuestiones no sean zanjadas, la belleza permanecerá inaprehensible. Pero el príncipe dice más: ella es un enigma. Por lo demás, lo más propio de toda palabra enigmática sea, tal vez, permanecer como un enigma, inclusive en el caso de que todo lo que la circunda haya sido clarificado. El Rin, ese canto hespérico de Hölderlin, sentencia al comienzo de la cuarta estrofa:

«Enigma, eso que puro ha brotado». «Énigme, ce que pur a jailli».

\section{(Traducción de Jean Beaufret)}

¿Cómo vamos a enfrentar no sólo el enigma de la belleza, sino ese enigma en el enigma que propone el Idiota: «La belleza salvará al mundo»? Quizás nuestra situación, después de que el apocalipsis ha tenido lugar -como dice Vladimir Benjaminovitch Bibikhin ${ }^{14}$ - nos es, paradójicamente, favorable; en esto: no podemos ya estar distraídos en ella por ninguna expectativa [espoir] ${ }^{15}$. ¿Cuál es nuestra situación?

14 En 2015, presentando un texto de Bibikhin, Philippe Arjakovsky escribe: «Vladimir Véniaminovitch Bibikhine es un filósofo ruso, que nació en 1938 y murió en 2004. Filólogo de formación, fue durante varios años secretario (privado) del filósofo Alexis Lossev, y, bajo el régimen comunista, trabajó esencialmente en la sombra, dedicándose en primer lugar a un importante trabajo de traducción (tanto de autores antiguos -los Presocráticos, Nicolás de Cusa, Gregorio Palamas, Dionisio Aeropagita, Petrarca - como de modernos -Wittgenstein, Sartre y, sobre todo, Heidegger, en particular con una traducción de Ser y tiempo). Sólo en 1989 ha podido dedicarse a enseñar públicamente en la Universidad de Moscú. Desde el momento de su muerte, su esposa edita el conjunto de sus cursos y de sus ensayos». La amistad entre Bibhikin y Fédier está retratada en el escrito de este último titulado «En Rusia», publicado en la Revista de Filosofía de la Universidad de Chile, Vol. 64, Santiago, 2008, pp. 231-247. Trad. de Jaime Sologuren y Jorge Acevedo.

15 Varlam Chalamov, Kolyma II, La Nuit (París, Ed. Maspéro, 1981, p. 316): «Un 
Es la del nihilismo. El nihilismo, que en los tiempos de Nietzsche y de Dostoievski no estaba aún sino a nuestras puertas, ya se ha instalado por todas partes, bajo su aspecto aparentemente más anodino: la uniformidad mundial [mondiale]. El término «globalización» [«mondialisation»] -que en Francia designa el proceso en curso del acabamiento de la racionalización de la economía planetaria-, este mismo término debería hacernos aguzar el oído. Porque la «globalización» [«mondialisation»] es de hecho el fenómeno de la pura y simple desaparición del mundo [monde] detrás de la totalidad de lo real (no carece de interés advertir que esos dos vocablos, «total» $y$ «real», han aparecido casi en la misma época, hacia fines del siglo XIV). Repitamos: Heidegger da la característica más aguda del nihilismo cuando lo presenta como la época de la historia en la que el ser se supedita enteramente al ente.

En la época del nihilismo acabado el hombre es totalmente requerido por la movilización total de lo real. Tal es, precisamente, la situación de eclipse del mundo en la que nosotros vivimos: esa en la cual «mundo» no designa ya para nosotros la integridad de las regiones de las que nosotros los hombres no somos sino una parte, sino el lugar de lo real donde el hombre, traicionando su humanidad, tiende a ocupar todo el sitio.

Esta época es un tiempo nocturno. Cuando Hölderlin declara cuál es nuestra popularidad (es en la segunda carta a Böhlendorf, fechada el 2 de diciembre de 1802), la designa, como ya lo hemos dicho, sobriedad. La palabra en alemán, Nüchternheit, resuena directamente en nocturnus. La sobriedad es la regla de vida cuando es de noche. Todos los poetas de este tiempo (y cuando digo poetas digo, al mismo tiempo, todos los artistas) han hecho la experiencia de la naturaleza nocturna de nuestro tiempo. Es quizás René Char quien la

hombre que está a la expectativa [espoir] de algo cambia su comportamiento, transige más a menudo con su consciencia que un hombre que no está a la expectativa de algo». Es preciso, imperativamente, distinguir la expectativa [espoir] de la esperanza [espérance]. La expectativa no es sino la deformación hipostasiante de la pura posibilidad de espera [attente] que abre simplemente la esperanza. (Nota de F. Fédier). [Cfr., V. Shalámov. Relatos de Kolimá, Ed. Minúscula, Barcelona, 2009. Trad. de Ricardo San Vicente]. 
ha experienciado más virilmente; cierra la recopilación Hojas de Hipnos (1943-1944), dedicada a su amigo Albert Camus, con el aforismo:

«En nuestras tinieblas, no hay sitio para la Belleza. Todo el sitio es para la Belleza». ${ }^{16}$

Todo el sitio para la Belleza, en nuestras tinieblas: ¿no es eso el colmo de la paradoja? Ciertamente, no, si meditamos lo que dice el Idiota: La belleza salvará al mundo.

¿Por qué tendría que ser salvado el mundo? ¿Estaría en peligro? Pero, en sentido propio, el mundo no puede estar en peligro, porque no es alguna cosa, ni tampoco la suma de los entes. El mundo no puede sino desaparecer. Salvar al mundo no podría, pues, venir a ser lo mismo que llevarlo a un lugar seguro [le mettre en sécurité].

Salvar, esto es salvare. Ernout y Meillet observan que en el bajo latín salvo «reemplaza a servo, al que no correspondía ningún adjetivo». El adjetivo correspondiente a salvo es, en efecto, salvus, que se conserva todavía entre nosotros en la locución «sano y salvo».

Salvus es, en latín, la palabra que corresponde -hasta en su etimo-

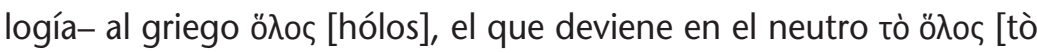
hólos]. Si queremos traducir salvus permaneciendo fieles al espíritu de la lengua, es preciso, pues, partir de la integridad.

El mundo no puede ser salvado sino bajo una condición. Digámoslo en latín: bajo la condición de que nosotros seamos universi -no «universales», sino completamente enteros (en un único impulso) vueltos hacia lo entero-. Tal es la conditio (la cum-ditio, ahí donde se ponen juntos gracias a una mutua dación; o bien, la cum-dicio, ahí donde se dicen juntos gracias a una conversación mutua -la donación y el diálogo son, entre los hombres, los bellos emblemas [mimiques] de datio y dicio); tal es LA condición humana.

16 Cfr., René Char. Antología. Estudio preliminar de René Ménard. Ediciones del Mediodía, Buenos Aires, 1968, p. 98. Trad. de Raúl Gustavo Aguirre / R. Char. Hojas de Hipnos, Ed.Visor, Madrid, 1973, p. 71. Trad. de Edison Simons. 
En todas partes donde viven los hombres, el sello de la humanidad en ellos aparece en su relación con lo que es bello.

Lo bello. ¿Qué es lo bello? Tratemos de decirlo hic et nunc, es decir, en el emplazamiento y en la época en la que nosotros estamos, lo que exige que no nos olvidemos que nosotros no estamos sino en preparación para eso.

Baudelaire, que también ha experienciado cuáles eran nuestro emplazamiento y nuestra época, escribe en 1855 :

«Mal que les pese a los sofistas demasiado altivos que han adquirido su ciencia en los libros, y por muy delicada y difícil de expresar que sea mi idea, no desespero de conseguirlo. Lo bello es siempre bizarro». ${ }^{17}$

(Exposición universal de 1855)

Es una declaración que nos es preciso comprender en toda su sobriedad. «Bizarre», en nuestra lengua francesa, señala un efecto de desviación, de desplazamiento, de discrepancia -una ruptura entre lo que nosotros esperamos por hábito y lo que nos llega perturbando lo habitual-. Recordando anteriormente uno de los momentos de la determinación de lo bello en Kant, habíamos apuntado sobre eso que ahora podemos denominar la «extrema rareza» [«bizarrerie»] de su formulación. La idea de un «placer universal», decíamos, limita con el sinsentido. Mientras no hagamos la diferenciación entre el placer y la satisfacción, mientras no comprendamos la satisfacción como el sello de una regulación natural, nos es imposible, en efecto, vislumbrar lo que es el verdadero placer, es decir, la relación entera de un ser humano a lo que, de forma extraña [bizarrement], le señala lo entero.

17 Cfr., Charles Baudelaire. «Exposición Universal -1855 - Bellas Artes. En Salones y otros escritos sobre arte, Antonio Machado Libros, Colección La balsa de la Medusa,

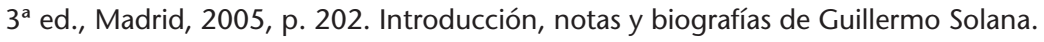
Trad. de Carmen Santos. 
El vislumbrar [entrevoir], esa relación singular (en la que toda individualidad, como tal, es abolida de entrada, en el momento mismo en que un ser humano llega a ser, por fin, enteramente ese que es), exige que se abandone lo que Baudelaire llama un poco antes, en ese mismo texto, la actitud del «profesor-jurado, especie de tiranomandarín». Este último, agrega él, «me hace siempre el efecto de un impío que sustituye a Dios» ${ }^{18}$.

¿Qué es la sobriedad? Hemos dicho anteriormente que era la regla de vida cuando es de noche. Cuando es de noche, reina la mezcla de todo (como dice el antepenúltimo verso del poema El Rin ${ }^{19}$ ). Ser impío, en tiempos nocturnos, es no saber mantener las diferencias, no saber diferenciar lo que, delante de nosotros, tiende a confundirse. La sobriedad -la «santa sobriedad», dice inclusive Hölderlin- consiste, pues, en mantener en la noche la mirada que distingue. Continuar, entonces, con lo que ha llegado a ser casi imposible, diferenciar; es no mostrarse impío. La devoción [pieté] es, así, el ejercicio más alto de la sobriedad. Pius es, como Eneas ${ }^{20}$, aquel que no habiendo nunca acabado de expiar, llega a mantener la pureza.

Lo que voy a decir ahora, lo debo a la observación de Dietrich Eberhard Sattler, cuyos dos últimos tomos de su edición íntegra de Hölderlin, los Cantos hespéricos (Die Vaterländische Gesänge), están en prensa en este momento.

En el poema, desde todo punto de vista único que es En adorable azul [En bleuité adorable], se encuentran, en la primera tríada, cinco palabras en las que se resume enteramente todo lo que he procurado decirles esta tarde.

18 Ibíd.

19 Cfr. F. Hölderlin: Himnos tardíos. Otros poemas, Ed. Sudamericana, Buenos Aires, 1972, p. 69. Trad. de Norberto Silvetti Paz / F. Hölderlin. Poesía completa, ed. bilingüe, Tomo II, Ediciones 29, Barcelona, 4ª ed., 1984, p. 123. Trad. de Federico Gorbea.

20 Véase, Virgilio. La Eneida, Ed. Universitaria, Santiago de Chile, 2010; por ejemplo, p. 67 (Libro I, verso 378). Editores: Nicolás Cruz y Antonio Arbea. Trad. de Egidio Poblete / Virgilio. Eneida, Ed. Gredos, Madrid, 1992, p. 151. Trad. de Javier de Echave-Sustaeta. 
Estas cinco palabras son las siguientes:

«Reinheit aber ist auch Schönheit».

«\{la\} Pureza, no obstante, es también Belleza». ${ }^{21}$

¿Cómo comentar estas palabras? ¿Cómo acompañar, pensando, las palabras gnómicas del poeta? Yo podría decir: en la época nocturna del nihilismo, la pureza es ya belleza en ella sola -en cuanto que ella mantiene la diferenciación.

Pero dejemos, más bien, el comentario a otro poeta. Hacia el final de Alquimia del verbo, escribe Rimbaud:

«Todo eso ha pasado. Hoy sé saludar a la belleza»².

El nihilismo en efecto está pasando. Saber SALUDAR a la belleza, en efecto, no es otra cosa que mantener sana y salva, en toda su pureza, la armonía inaparente en que palpita el corazón del mundo.

21 Véase el poema en: Breno Onetto M. «Hölderlin: Revolución y memoria», Be-uvedráis Eds., Santiago de Chile, 2002, pp. 128 s.

22 Cfr. A. Rimbaud: Obra poética y correspondencia escogida, ed. bilingüe. UNAM, México, 1999, p. 289. Trad. de José Luis Rivas y Frédéric-Yves Jeannet / A. Rimbaud: Poesía completa, Ediciones 29, Barcelona, $16^{a}$ ed., 1994, p. 100. Trad. de J. F. VidalJover. 